\title{
Examining offender, victim and offence characteristics in cases of stranger child abduction: An exploratory comparison of attempted and completed cases using publicly available data from the UK
}

Craig John Robert Collie and Karen Shalev Greene

\begin{abstract}
:
The article examines the demographic features of victims and offenders involved in cases of stranger child abduction in the UK, performing a quantitative, secondary data analysis of a sample of 78 offences that have received a conviction in the UK since 1988. Information was gathered via a study of media and legal databases. The profiles of attempted and completed cases of stranger child abduction are compared to ascertain the relationship between case characteristics and offence outcome.
\end{abstract}

Findings indicated that while females victims are targeted more frequently overall, male victims are at greater risk of being abducted successfully by strangers. Females are more likely to be approached by non-specialist offenders, whereas male victims are more likely to be targeted by chronic child sex offenders. Victims aged 10 were found to be at risk of being victimized successfully, while attempted victimization was even across all victim age groups. Finally, older offenders were found to be more persistent, with younger offenders discontinuing their offence earlier in the behavioural sequence.

The implications of these findings are discussed and recommendations for future research made. The continued analysis of abduction offences utilizing the attempted-completed distinction is also strongly encouraged and endorsed. 


\section{Introduction:}

Despite being of interest to the police, media and the public (see, e.g., Griffin \& Miller, 2008 Hanfland, Keppel \& Weis, 1997; Spilman, 2006), stranger child abduction remains a poorly understood offence. There are a number of reasons for this gap in knowledge. Firstly, stranger child abduction is often discussed alongside other forms of child abduction, particularly family abductions and acquaintance abductions. Each of these abduction types is recognized as being distinct (Asdigian, Finkelhor \& Hotaling, 1995). However, initial studies treated stranger and acquaintance abductions under the single heading of "non-family" abduction. In spite of recommendations to study each of the three types separately (Asdigian et al, 1995), some studies still inappropriately conflate stranger child abduction with acquaintance abduction (e.g., Beyer \& Beasley, 2003; Ericson \& Friendship, 2002). Additionally, some studies discuss stranger child abduction alongside and also conflate figures with other offence similar domain offence types, e.g., child molestation, (e.g., Prentky et al, 1991; Lanning \& Burgess, 1995), while others discuss abduction in broad terms without explaining whether they refer to all abductions or to child abductions specifically (e.g., Fitzgerald \& People, 2006). This leads to the issue of there being very few studies where it can be reliably said that the data relates purely to stranger child abduction, which results in the demographic picture of this offence being obscured and uncertain.

Secondly, while many studies examining stranger child abduction measure demographic details of victims and offenders, they tend to record only the most basic information pertaining to victims and offenders. A review of existing studies that purport to provide information on stranger child abduction (see Section 1.1) reveals that victim gender and sex is recorded by most studies. However, only a small handful of studies give details as to the age of offenders, with fewer still giving details as to their offending history. As a result, while many studies feature large sample sizes, they feature limited levels of demographic detail. 
This means that they have few variables with which to compare to one another and carry out analysis.

This has left a number of notable gaps in the current understanding of the profile of stranger child abduction, for instance, little information exists regarding the offence histories of stranger child abductors and how this interacts with other offence variables such as victim age or sex preference; while we know the ages of offenders involved in stranger child abduction, we do not know if this interacts with crime scene behaviours. In favour of a more detailed approach, reference can be made to the study carried out by Boudreaux, Lord and Dutra (1999), which, by gathering detailed case information, showed that victims of school age are the most likely to be targeted by abductors, and that offender motive interacts with victim sex when selecting victims.

Finally, until very recently, studies examining stranger child abduction have not taken into account whether the abduction was completed or not. This important outcome variable has been used to ascertain the predictive power of various offence features, giving additional relevance even to simple variables such as age and sex. Scrutinizing the proportions of these variables that appear in attempted compared to completed cases can allow theorizing as to why certain abductions are successful while others are not. This means that even those few studies that have gathered demographic details regarding stranger child abduction have not made the most powerful use of these figures by failing to consider them alongside case outcome. Therefore, Gallagher, Bradford and Pease (2008) recommend that all future studies examining stranger child abduction should do so by comparing attempted and completed cases.

This article seeks to address these issues by, firstly, assembling a dataset that clearly includes only cases of stranger child abduction; secondly, by gathering a relatively small but detailed 
sample that allows for more variables to be coded and subsequently compared; and thirdly, to examine and compare the profiles of both completed and attempted cases of stranger child abduction, in order to ascertain which variables, if any, have an impact on case outcome.

\subsection{The Existing Picture of Stranger Child Abduction}

As one might expect given the limitations outlined above, findings that purport to describe the demographic profile of stranger child abductions have been mixed, resulting in a number of competing perspectives. The most common data recorded pertains to victim age and to victim sex. As can be seen in Table 1, some studies have shown the gender split to be largely even (Finkelhor, Hotaling \& Asdigian, 1995; Gallagher, Bradford \& Pease, 2008), whereas others have found females to be over-represented at rates ranging from the $60-65 \%$ (Finkelhor \& Ormrod, 2000; Rodreguez, Nahirny, Burgess and Burgess, 1998; Miller, Kurlycheck, Hansen \& Wilson, 2008) to 81\% (Asdigian, Finkelhor \& Hotaling, 1995).

Some studies have found that stranger child abduction is most strongly associated with older victims, with reports indicating peaks of victimization between 13 years and 16 years (Finkelhor \& Ormrod, 2000; Gallagher, Bradford \& Pease, 2008; Miller et al., 2008; Finkelhor, Hammer \& Sedlak, 2002). Other studies, however, indicate that younger victims, aged 10-11 years, are most at risk (Boudreaux, Lord \& Dutra, 1999; Gregoire, 2010; Newiss \& Fairbrother, 2004). The study by Boudreaux, Lord and Dutra (1999) goes some way to explaining why there are differences in age and gender. They show that offenders are likely to prefer school aged victims, particularly around the age of 10 years, as they are the least defended. Victims at other ages are more likely to either defend themselves or to be guarded by other actors, such as parents.

Offender characteristics are recorded less often, although findings tend to be more consistent than those dealing with victims. It has been consistently and overwhelmingly shown that 
males are vastly over-represented as offenders in stranger abduction cases (Gallagher et al., 2008; Finkelhor et al., 2002; Miller et al., 2008; Boudreaux, Lord \& Dutra, 1999). Reports range from $86 \%$ of stranger child abductors being male (Finkelhor, et al., 2002) to 98\% (Boudreaux et al., 1999). A sub-type of stranger child abduction, involving maternal desire, is dominated by female victims (Ankrom\& Lent, 1995; Baker et al., 2003). However, this is distinct from the current topic of study. Similarly, studies examining the age of offers found that, although stranger child abductors can be of any age, the majority of offenders are aged in their mid to late 20s (Finkehlor et al., 2002; Gallagher, et al., 2008; Gregoire, 2010; Bourdreaux, Lord \& Dutra, 1999). That said, as of yet, no study has analysed how an offender's age influences the properties of stranger child abduction cases.

There have been particularly interesting findings relating to offender background. Stereotypes of stranger child abductors would suggest that all such offenders are predatory paedophiles with specialised offending interest in children. However, it has been found that stranger child abductors tend to have either a diverse criminal, with a majority (75\%) of child abducting offenders and other similar offenders (Liu, Francis \& Soothill, 2007) having perpetrated a range of offence types, and a smaller number (25\%) having no offence history at all (Beasley, et al., 2009; Langevin, 2006; Gregoire, 2010). These findings suggest extremely low levels of specialisation among child abductors. As with offender age, the effect of such background on case outcome remains un-researched.

There is little information available regarding even quite basic offence features. The time of day at which offences occur. Finkelhor and Ormrod (2000), who split the day into four blocks of six hours, found that stranger child abductions most frequently occur in the afternoon (noon till 6pm), at $44 \%$ of the time, followed closely by evening (6pm till Midnight). A notable amount (15\%) occurred in the morning (6am till Noon), with the fewest occurring at night (Midnight till 6am). By far the most specific study was carried out by Miller, 
Kurlycheck, Hansen \& Wilson (2008), who were able to analyse the time of the offence down to the hour. Their examination of all abductions showed that offending was most likely to occur between 2pm and 9pm, what they referred to as "the afterschool and evening hours". When controlling for stranger offenders specifically, a very similar pattern emerged, with a peak at around 4pm, with an additional unusually high number between 8 and 9am, which incidentally coincides with the time that children would normally be on their way to school.

Overall, the key trends between these studies is that offending tends to occur after what could be considered school hours and into the early evening, albeit with additional peaks early in the day. Miller et al. (2008) also broke down the rates at which various abduction types happened on each day of the week, finding that offences were spread evenly across the week, with the exception being that Sunday had somewhat fewer offences.

The location of offences is also uncommonly recorded. However, a number of location characteristics are commonly agreed upon. Miller et al. found that most 74.1\% of offences occurred away from the home, with $45.7 \%$ occurring on "highways". Finkelhor, Hotaling \& Sedlak (1992) similarly found that most non-family abduction offences occur in public, with $32 \%$ occurring in a street or car, $25 \%$ in a park or woodland and $14 \%$ in other public areas. $18 \%$ occurred in other homes or yards, with very few $(<1 \%)$ occurring in stores. Finkelhor \& Ormrod (2000) found stranger abductions to mostly occur outdoors (58\%) in locations like “streets, highways, parks, waterways and other public areas”. 225 occurred in a residence or home, $17 \%$ in an "other building”, i.e., non-residential indoor location, and 3\% at schools. In all, stranger child abductions appear to occur predominantly in public and outdoors, with street areas being repeatedly cited as the most common offence site. 
With regard to offender race, UK studies have found offenders to be predominantly white. Newiss \& Fairbrother report 90\% incidence of white offenders, with others finding that race plays such a small role that it was not reported (Gallagher et al., 2008).

From this, a tentative profile of key recurring features of stranger child abduction can be drawn. However, little to no further analysis of demographic information such as this has been carried out in existing studies. It is unclear the extent to which, e.g., that an offender's background influences other features of their offences. Additionally, very little work has been done to examine how these features differ between attempted and completed cases.

\subsection{Attempted and Completed Cases}

As mentioned, there has been a call for more studies to take into account the effects of various offence features on the outcome of cases of stranger child abduction (Gallagher, Bradford \& Pease, 2008). As of yet, few studies have examined the ways in which factors pertaining to stranger child abduction impact on case outcomes, with only a small number even recording the rates at which offences are completed (Newiss \& Fairbrother, 2006; Newiss \& Traynor, 2013) with only one study examining attempted cases in detail (Finkelhor, Hotaling \& Asdigian, 1995). Those studies that examined this dimension have produced differing evidence as to the impact case outcome might have, with Finkelhor et al. (1995) reporting hardly any variance, but Newiss \& Fairbrother noting quite different trends in demographic profile.

The potential relevance of attempted abductions was briefly alluded to in the first National Incident Studies of Missing, Abducted, Runaway and Throwaway children (NISMART) study (Finkelhor, Hotaling \& Sedlak, 1992), where findings implied that families had experienced 114,600 attempted abductions against children compared to the just 3200 reported in 1988, and that among these the vast majority was carried out by a stranger in a 
passing car (Finkelhor et al., 1992). With the exception of a single study which revealed no information on victims or offenders (Finkelhor, Hotaling \& Asdigian, 1995), attempted cases were not discussed again for some time. Newiss and Fairbrother's (2006) examination of the composition of child abduction offences found that $47 \%$ of all abductions, consisting of 128 offences, involved an attempted abduction by a stranger involving very little or even no actual contact between the offender themselves and the victim, whereas only $9 \%$ of abduction offences were successful stranger abductions. Gallagher et al. (2008) found that 1 in 59 children in the UK would suffer an abduction attempt against them at some point during their childhood. They found that only $9.8 \%$ of stranger child abductions became successful. Most recently, Newiss and Traynor (2013) found that up to 75\% of stranger child abductions reported to the police were attempted cases. From this limited set of information, it can be safely concluded that the vast majority of stranger child abduction cases are attempts only.

Therefore, the aim of this study is to examine the demographic features of victims and offenders involved in cases of stranger child abduction in the UK, and to establish the extent to which offenders and victims' profiles differ depending on case outcome. This comparison will enable identification of case features and demographic trends that have associations with cases where the abduction attempt is completed, and to discuss the mechanisms underlying such association.

To ensure that all cases featured only incidents of stranger child abduction, terms were defined as follows: A stranger child abduction occurs when a person makes any effort to take unlawful control of a child over with whom they have had no prior contact (Newiss \& Traynor, 2013). A child is deemed to include anyone under the age of 18 (HM Government, 2015). The child's acquiescence is irrelevant to whether the offence is considered completed, as they cannot legally consent to being unlawfully controlled (Finkelhor, Hammer \& Sedlak, 2002). 
For the reasons outlined above, the data available regarding stranger child abduction is limited, however, given the findings detailed above, it is hypothesized that there will be a difference in the demographic profiles between attempted and completed cases of stranger child abduction. Aside from that, this study is exploratory in nature and seeks to provide additional information regarding the features of stranger child abduction, particularly demographic features as well as basic offence features.

\section{Materials and Method}

The study was carried by quantitative analysis of secondary data gathered pertaining cases pertaining to 78 stranger child abduction incidents that occurred in the UK between 1988 and 2014. 85\% of cases occurred after the year 2000 .

\subsection{Data Gathering Procedure}

This is a UK based study and all cases referred to took place in the UK. All data was gathered by the first author from publically available sources. The types of data utilized included: legal reports, including transcripts of legal decisions and court cases; and newspaper articles reporting on offences and their related trials in court. Media sources were utilized since, in the UK, the majority of legal hearings are not made recorded unless they have an impact on the common law. As a result, media sources reporting on the events of a trial become the most direct data available on these proceedings. The authors made an attempt to access police records as well; however, the recording practices in the databases made available meant it was not possible to suitably differentiate between stranger and acquaintance cases, resulting in this data not being usable. 
Legal cases were gathered by searching the legal databases Westlaw and Lexis using combinations of the keywords “'Stranger', ‘Child', ‘Abduction’, ‘Sexual’, ‘Assault' and 'Kidnap’. Media reports were gathered using the specialised database Lexis, as well as the open source search engines Google and Yahoo. These were searched using the same keywords, with the additional terms 'charged', 'guilty', and ‘convicted’ being applied. Additional searches using these keywords were carried out on the individual websites of each media outlet utilized.

Table 1: Search Key Words

\begin{tabular}{lll}
\hline & \multicolumn{2}{c}{ Key Words } \\
& Searched & \\
\hline Stranger & Guilty & Assault \\
Child & Charged & Sexual \\
Abduction & Kidnap & Attack \\
Convicted & & \\
\hline
\end{tabular}

Table 2: Local and National UK Media Outlets Searched

$$
\text { Media Outlets Searched }
$$

\begin{tabular}{lll}
\hline The Independent & The Telegraph & $\begin{array}{l}\text { The Birmingham Evening } \\
\text { Mail }\end{array}$ \\
\hline The Guardian & Hull Daily Mail & The Northern Echo \\
\hline The Journal & Bradford Telegraph \& & The Mirror \\
& Argus & \\
\hline BBC News & Gloucester Citizen & The Daily Mail \\
\hline
\end{tabular}




\begin{tabular}{lll}
\hline The York Press & Morley Observer & Birmingham Mail \\
\hline Walsall Advertiser & Hastings Observer & Bolton News \\
\hline The Northern Echo & Burnley Express & Newham Recorder \\
\hline Lives News & Welwyn Hatfield Times & Lancashire Telegraph \\
\hline Mancunian Matters & North of England News & Dorset Echo \\
\hline Northampton Chronicle \& & The Sun & North Wales Daily Post \\
Echo & Yorkshire Evening Post & Yorkshire Post \\
\hline Express and Star & Huffington Post UK & ITV News \\
\hline Rotherham Advertiser & Doncaster Free Press & Belfast Telegraph \\
\hline Evening Standard & Keighley News & Stroud News \& Journal \\
\hline Sunderland Echo & Wigan Today & Leigh Journal \\
\hline Hull Daily Mail & Western Daily Press & Bristol Post \\
\hline Blackpool Gazette & Bury Times & Manchester Evening News \\
\hline Telegraph \& Argus & Kent and Sussex Courier & Kent Online \\
\hline The Herald & The Glasgow Herald & \\
\hline
\end{tabular}

\subsection{Validity and Reliability}

Measures were taken to assist in ensuring as much validity as possible when using secondary information such as this. Firstly, only cases involving a confirmed conviction were analysed. This was done with the purpose of ensuring that there was an identifiable offender, and that the facts relating to their case had been sufficiently corroborated to result in a legal conviction. The conviction did not have to be for child abduction or kidnap precisely, as such charges are often subsumed by a larger, more serious conviction at trial. Inclusion was therefore based on convictions that involved behaviour where the offender takes or detains, or attempts to take or detain, a child. Secondly, only reports where there was an identifiable individual offender were used in order to ensure that all sources related to the same case. Thirdly, as many sources as possible pertaining to each case were utilized in order to verify 
reports. Each case utilized featured a confirmed conviction, as well as at least one media report corroborating details of the case. This meant that, in addition to the UK legal system having deemed there to be sufficient evidence to convict the offender, that multiple outlets had confirmed details of the incident.

Due to the limited availability of subjects, an availability sampling strategy was utilized to identify as many cases as possible that fit the inclusion criteria. Approximately 90 additional cases in addition to those ultimately utilized were considered for inclusion, but were rejected due to either lack of corroborating information, inconsistency between sources, inability to identify a named offender or confirmed conviction, or because the victim-offender stranger relationship was uncertain.

\subsection{Coding}

All sources of data pertaining to each individual case were compiled, with this raw data being used to produce profiles of each offence. Profiles including as much detail as possible were created regarding the features of each offender, each victim, the nature of the offence in question, and the offence's outcome. These details were coded into SPSS, and their features measured utilizing SPSS’ analytical functions.

The key variables analysed in this research were victim sex; victim age; offender age; offender's criminal history; and case outcome. A small number of additional variables relating to offence characteristics were examined, including time of day; day the offence took place; and location the offence was initiated. If any information was absent or uncertain in a given case, the relevant fields were left blank and that case was not counted.

Victim sex was coded simply according to how the victim was identified in the data available. 
Victim Age was coded again according to the age, in years, specified in the data. In addition, victim age was grouped.

Offender age, similarly, was coded according to the age, in years, reported by the data. Offender age was grouped.

Offending History was coded based on the overriding character of the previous offences attributed to the offender in the data. The offender was coded as violent if their offences predominantly involved assaultive and aggressive, non-sexual acts; as sexual if their history was characterised by sexual acts against adults, or a mixture of adults and children; as chronic child sex offenders if their history consist of only or predominantly repeated sexual offences targeted specifically against victims aged under 18 (see, e.g., Jennings, 2015); and general offenders where the offending background included a variety of offences, including property offences; and no offending history was recorded if the offender was reported to have no prior convictions (see Beasley et al., 2009).

Offence Outcome was coded depending on whether an abduction event had been completed in law. If an offender had completed the act of taking control over a child, the event was coded as a completed abduction. If the offender had not completed such an action, but there was clear evidence that they had made an effort to do so, the case was coded as an attempted abduction.

Area of the Offence was coded according to the general description of the area provided by the case file. The codes utilized were developed based on those that have been identified in existing literature, and included streets and roads, wooded areas and parks, schools, city centres, shops, and with any other locations being categorized as "other". 
Time of Day was coded by dividing the day into 3 discrete sections of morning, afternoon and evening.

Day of the Week was coded simply based on the day of the week on which the offence took place.

\subsection{Analysis Procedure}

These features were subjected to initial descriptive tests, including production of frequency tables and examination of means. Additional descriptive tests were carried out with controls for case outcome in order to provide profiles of the features of attempted as well as completed cases.

Subsequent bivariate tests were carried out utilizing an association matrix to identify offence features that had significant interactions with demographic features of the offence. Inferential cross-tabulation analyses were performed using Pearson’s Chi-Square.

\section{Results}

Of the cases analysed, 32.5\% of involved attempted incidents of stranger child abduction, with $67.5 \%$ involving completed incidents of stranger child abduction. The proportions of attempted and completed cases present in each of the demographic features examined will be discussed in their relevant section below.

\subsection{Victim Characteristics}




\subsubsection{Victim Sex}

Victim sex overall. The sex split of victims represented in this study was roughly even, with $54.43 \%$ female and $45.57 \%$ male.

Victim sex and abduction completion. As Table 4 illustrates, the shape of the sex distribution alters greatly when differentiating attempted and completed cases. In attempted cases, females are represented far more often than males, being present in $64 \%$ of attempted cases. Conversely, and more surprisingly, males become the most common victim when examining only completed cases, present in $52.94 \%$ of cases, when they represented only $45.57 \%$ of victims in stranger abductions overall.

$\underline{\text { Table 3- Attempted vs Completed Cases: Victim Sex }}$

Attempted Completed Overall

Male $\quad 36 \%(n=9) \quad 51.79 \%(n=29) \quad 46.91 \%(n=38)$

Victim Sex Female $\quad 64 \%(n=16) \quad 48.21 \%(n=27) \quad 53.09 \%(n=43)$

Total $100 \%(\mathrm{~N}=25) \quad 100 \%(\mathrm{~N}=56) \quad 100 \%(\mathrm{~N}=81)$

As such, there is a clear difference between attempted cases and completed cases when we control for sex.

\subsubsection{Victim Age.}


Of the 81 victims represented in the full dataset, it was not possible to discern the exact ages of 3 . The figures in this section refer to the 78 victims whose ages were discernible.

The age range was 2-17 years. This range of victim ages ran almost the entire range of possible ages to be considered a child for the purposes of stranger child abduction.

Victims were, on average, 10.86 years old. There was a standard deviation of 3.078 from that mean. This places the mean at roughly the middle range of possible ages.

10 years was also the most represented age, with 14 (17.9\%) victims being 10 years old at the time of the offence. The next most frequent ages were 13 (14.1\%), 11 (12.8\%), 14 (10.3\%) and $12(10.3 \%)$ years, with the least represented ages being at either extreme of age- the ages of 2 years and 3 years, and 17 years, were represented by single victims. There was significant drop off at the age of 15 years. Given the small range of ages represented, the data's distribution roughly follows a standard distribution, with only the ages of 10 years and 13 years being notably over-represented. 


\subsubsection{Comparing Attempted and Completed Abductions ${ }^{1}$}

Table 4- Victim Age Group by Offence Outcome

\begin{tabular}{ccccc}
\cline { 3 - 4 } & & Attempted & Completed & Overall \\
& & & & \\
\hline \multirow{3}{*}{ Victim Age } & $2-9$ Years & $44 \%(\mathrm{n}=11)$ & $20 \%(\mathrm{n}=11)$ & $27.5 \%(\mathrm{n}=22)$ \\
& $10-15$ Years & $56 \%(\mathrm{n}=14)$ & $72.72 \%(\mathrm{n}=40)$ & $67.5 \%(\mathrm{n}=54)$ \\
& $16-18$ Years & $0 \%(\mathrm{n}=0)$ & $7.27 \%(\mathrm{n}=4)$ & $5 \%(\mathrm{n}=4)$ \\
& Total & $100 \%(\mathrm{~N}=25)$ & $100 \%(\mathrm{~N}=55)$ & $100 \%(\mathrm{~N}=80)$ \\
\hline
\end{tabular}

In the 25 identified attempted cases of stranger child abduction where age was discernible, 11 (44\%) victims were aged 2-9, 14 (56\%) were aged 10-15, and none were aged 16-18. The victim's age ranged from 2-14. The average age was slightly lower than in overall abductions, at 9.67 (SD 3.332).

In the 55 completed cases, 11 (20\%) victims were aged 0-10, 40 (72.73\%) were aged 11-14, and 4 (7.27\%) were aged 16-18. Their ages ranged from 3 to 17, with a mean age of 11.11 (SD 2.792).

The pattern observed in completed cases is very similar to the patter observed in child abduction overall. The average age is once again 10 , and is vastly over-represented. This becomes even more pronounced, as, unlike with the overall figures, there is no accompanying peak observed at age 13. As such, in completed cases, 10 appears to be an age of particular significance.

\footnotetext{
${ }^{1}$ Pearson's Chi-Square showed significant association between offence outcome and victim age group, $X^{2}(2, N=80)=6.131, p=0.047$.
} 
However, the pattern changes significantly when attempted cases are examined. The age distribution does not comfortably follow a distribution curve. There are large peaks in victimization at ages 8 and 13, with victimization also being high at ages 10, 11, 12 and 14 . This seems to indicate that victims both slightly older as well as slightly younger than 10 are also being victimized to a significant degree; however the offences against them are more commonly going uncompleted.

\subsection{Offender Characteristics}

\subsubsection{Offender's Sex}

As discussed above, $100 \%$ of the offenders in the sample were male due to inclusion criteria allowing only for male subjects.

\subsubsection{Offender's Age}

Offender Age Overall. The youngest offender in the sample was 18 years old (the youngest age suitable for inclusion), with the oldest offender being aged 59 years old at the time of the offence. The average age of offender was 35.05, with a standard deviation of 10.582. It was not possible to determine the age of $11.3 \%(n=7)$ offenders. Where an offender was responsible for multiple offences, the above calculations used their age at the first known offence, when known. 
Offender Age in Attempted and Completed Cases. In cases that became attempts $(n=24)$, the average offender age was 31.83 years ( $S D=10.512)$. In cases where the offence was completed and age was known $(\mathrm{n}=30)$, the average offender age was 37.83 years ( $S D=10.151)$. As such, offenders in attempted cases were likely to be somewhat younger than offenders whose abductions were successful, although on average offenders remained in the mid-to-late 30’s age range when accounting for completion.

The age group of the offender was found to have a significant association with both whether the abduction element of the offence itself was attempted or completed $(\mathrm{p}=0.010)$, as well as whether any further offence took place against the victim, i.e., whether the abduction was escalated $(\mathrm{p}=0.018)$.

The pattern that emerged when comparing attempted and completed cases, as shown in Table 5, was that, on the whole, offenders in attempted cases were more likely to belong to the younger age category, whereas offenders in completed cases tended to belong to mid-range or older age groups. In cases where an effort was made to escalate the offence, while offenders generally were successful in doing so (70.3\%),the completion rate was somewhat higher for offenders in the mid-range age group (80\%) than it was for younger offenders (61.5\%), and was even less so for the oldest group (50\%).

Table 5- Offender Age Group at Time of the Offence by Offence Outcome

\begin{tabular}{lrrrrr}
\hline & \multicolumn{3}{c}{ Offender Age Group } & Total \\
\cline { 3 - 5 } & & $18-30$ Years & $31-49$ Years & $50+$ Years & N \\
\hline Offence & Attempted & $\mathbf{6 2 . 9 6 \% ( n = 1 7 )}$ & $19.05 \%(\mathrm{n}=4)$ & $42.86 \%(\mathrm{n}=3)$ & 24 \\
Outcome & Completed & $37.04 \%(\mathrm{n}=10)$ & $\mathbf{8 0 . 9 5 \% ( \mathbf { n } = \mathbf { 1 7 } )}$ & $57.14 \%(\mathrm{n}=4)$ & 31 \\
Total & & $100 \%(\mathrm{~N}=27)$ & $100 \%(\mathrm{~N}=21)$ & $100 \%(\mathrm{~N}=7 \%)$ & 55 \\
\hline
\end{tabular}




\subsubsection{Offender Age and Level of Post-Abduction Movement}

As revealed by the Matrix of Association, there was an additional significant effect for an offender's age group on whether the offender moved the victim to various crime sites following the initial abduction $((10, \mathrm{n}=54)=20.940, \mathrm{p}=0.021)$.

The younger group was much more likely to not have moved the victim. The most common reason for this was a failure to progress the offence to a point where abduction was successful This appears to indicate that younger offenders would be likely to give up their abduction attempt or otherwise fail to abduct their victim at an earlier stage of the offence than older offenders. The implications of this finding will be discussed below.

Table 6- Post-Abduction Victim Movement According to Offender Age

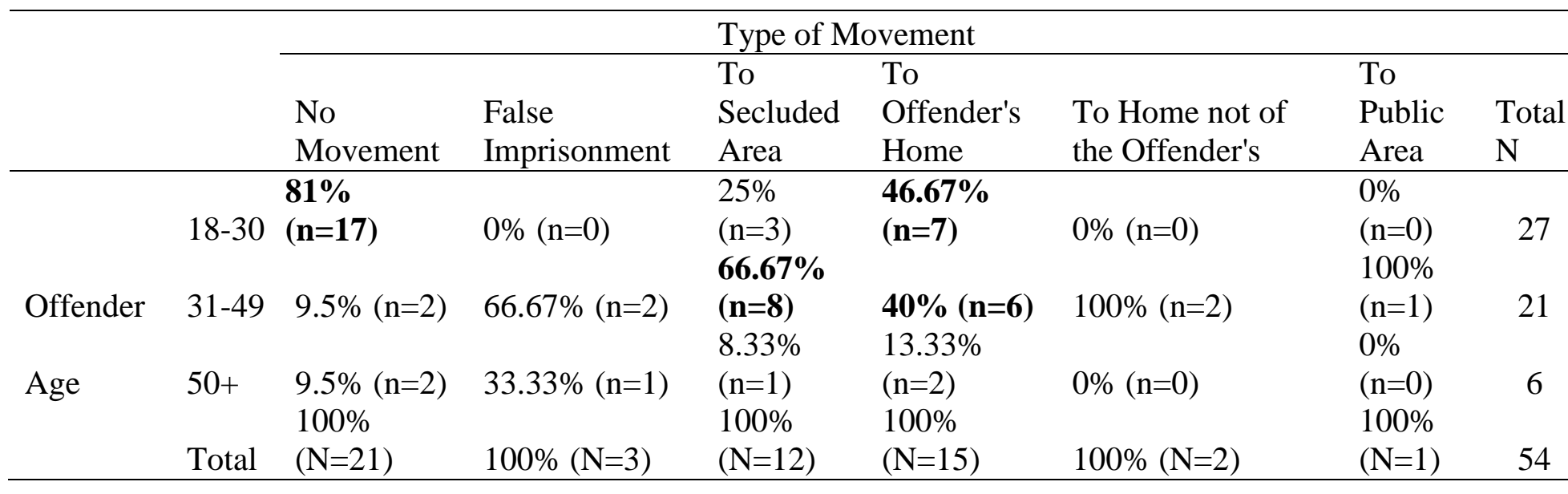

\subsubsection{Offending Background}


Results indicated that offenders in the sample had a diverse range of offending backgrounds.

Offenders could be categorized into groups that best described their overall offending history. 42.3\% had no recorded offending history at all, $20.5 \%$ were generalized offenders who had a range of convictions including property offending, violent offending and others, $17.9 \%$ were predominantly violent offenders, a relatively small proportion at 3.8\% were predominantly sex offenders, $3.8 \%$ had offending careers characterized by alcohol problems, with $11.5 \%$ being categorized as chronic child sex offenders. Note that, cumulatively, $15.3 \%$ of offenders could be considered sex offenders if general and child sex offenders were combined.

Table 7- Offending History and Offence Completion ${ }^{2}$

\begin{tabular}{ccccc}
\hline & & Overall Frequency & Attempted & Completed \\
\hline & & & & \\
& No Offending History & $33(42.3 \%)$ & $15(45.45 \%)$ & $18(54.54 \%)$ \\
Offending & Generalized Offending & $16(20.5 \%)$ & $6(37.5 \%)$ & $10(62.5 \%)$ \\
History & Violent Offending & $14(17.9 \%)$ & $5(35.7 \%)$ & $9(64.29 \%)$ \\
Type & Sex Offending & $31(39.7 \%)$ & $9(29 \%)$ & $22(71 \%)$ \\
& Substance Abuse Related & $4(5.1 \%)$ & $1(25 \%)$ & $3(75 \%)$ \\
& Any Child Sex Offending & $30(38.46 \%)$ & $5(16.67 \%)$ & $25(83.33 \%)$ \\
& Accessing Illegal Images & $2(2.56 \%)$ & $0(0 \%)$ & $2(100 \%)$ \\
& Chronic Child Sex Offending & $9(11.5 \%)$ & $1(11.11 \%)$ & $8(88.89 \%)$ \\
\hline
\end{tabular}

\footnotetext{
${ }^{2}$ Note that totals in each column are higher than $100 \%$ to reflect offenders whose histories included multiple offending types
} 
In terms of holding a conviction for any offence, $17.9 \%$ had been convicted of a violent offence, $39.7 \%$ of a previous offence, $5.1 \%$ for a substance abuse related offence, $38.46 \%$ of a sex offence involving a child, and $2.56 \%$ had been convicted for accessing illegal images of children.

\subsubsection{Victim Sex, Offender's Background: Male Victims and Chronic Offenders}

In order to test for significant interactions between the factors discussed alongside offence outcome, a matrix of association was created. This returned highly significant effects when comparing victim sex with offender background.

The test of association showed that there was a significant interaction between victim sex and offender background. This association was particularly strong for offenders with a history of chronic child sex offending.

Table 8- Chronic Child Sex Offenders by Victim Sex

\begin{tabular}{ccccc} 
& \multicolumn{3}{c}{ Victim's Sex } & Total N \\
\cline { 3 - 4 } & & Male & Female & Tol \\
Chronic Child & No & $61.11 \%(\mathrm{n}=22)$ & $92.5 \%(\mathrm{n}=37)$ & 59 \\
Sex Offender & Yes & $38.89 \%(\mathrm{n}=14)$ & $7.5 \%(\mathrm{n}=3)$ & 17 \\
& Total & $100 \%(\mathrm{n}=36)$ & $100 \%(\mathrm{n}=40)$ & 76 \\
\hline
\end{tabular}

Chronic Child Sex Offender ( $(1, N=59)=10.750, p=0.001)$ 


\section{Victim's Sex}

Male

Female

Total

No Offending History

$47.22 \%(n=17) \quad 35 \%(n=14) \quad 40.79(n=31)$

Generalized

$8.33 \%(n=3) \quad 32.5 \%(n=13) \quad 21.05(n=16)$

Previous offending

Violent

$11.11 \%(n=4) \quad 25 \%(n=10) \quad 18.42 \%(n=14)$

Sexual

$$
8.33 \%(n=3) \quad 0 \%(n=0) \quad 3.95 \%(n=3)
$$

Substance Abuse Related

$$
2.78 \%(n=1) \quad 5 \%(n=2) \quad 3.95 \%(n=3)
$$

Chronic Child Sex Offending

$$
22.22 \%(n=8) \quad 2.5 \%(n=1) \quad 11.84 \%(n=9)
$$

Total

$100 \%(\mathrm{~N}=36) \quad 100 \%(\mathrm{~N}=40) \quad 100 \%(\mathrm{~N}=76)$

$$
\begin{aligned}
& *(1, N=59)=10.750, p=0.001 \\
& * * X^{2}(5, \mathrm{~N}=76)=17.728, \mathrm{p}=0.003
\end{aligned}
$$

Offenders with a history of child sex offending were far more likely to select male victims, doing so in $88.87 \%$ of cases. On the one hand, offenders with a generalized or mixed criminal career were far more likely to target female victims. Offenders with general offence histories that included crimes of dishonesty, theft, sex and/or violence targeted females $81.25 \%$ of the time, and those with previous violent histories who had transitioned to sexual offences 
targeted females in $71.4 \%$ of cases involving such offenders. This was a statistically significant association, $X^{2}(5, \mathrm{~N}=76)=17.728, \mathrm{p}=0.003$.

\subsection{Timing of the Offence}

There was a fairly even distribution of offences across each day of the week, with the only notable trend being a slight increase in offences on Thursday, and a decrease on Wednesday. When comparing attempted and completed cases, there was a slight trend indicating that offences enacted on the weekend were less likely to become attempted cases.

Table 10: Day of the Week on Which the Offence Took Place

\begin{tabular}{|c|c|c|c|c|}
\hline & & All Offences & Completed & Attempted \\
\hline & Monday & $9.64 \%(n=8)$ & $14.29 \%(n=5)$ & $13.04 \%(n=3)$ \\
\hline & Tuesday & $10.84 \%(n=9)$ & $11.43 \%(n=4)$ & $21.74 \%(n=5)$ \\
\hline Day of & Wednesday & $4.82 \%(n=4)$ & $11.43 \%(n=4)$ & $0 \%(n=0)$ \\
\hline the Week & Thursday & $14.46 \%(n=12)$ & $25.71 \%(n=9)$ & $13.04 \%(n=3)$ \\
\hline & Friday & $8.43(n=7)$ & $14.29 \%(n=5)$ & $8.70 \%(n=2)$ \\
\hline & Saturday & $10.84 \%(n=9)$ & $8.71 \%(n=3)$ & $26.09 \%(n=6)$ \\
\hline & Sunday & $10.84 \%(n=9)$ & $14.29 \%(n=5)$ & $17.39 \%(n=4)$ \\
\hline & Total & $100 \%(\mathrm{~N}=58)$ & $100 \%(\mathrm{~N}=35)$ & $100 \%(\mathrm{~N}=23)$ \\
\hline
\end{tabular}

Table 11: Time of Day at Which the Offence Took Place 


\begin{tabular}{|c|c|c|c|c|}
\hline & & All Offences & Attempted & Completed \\
\hline \multirow{5}{*}{ Time of Day } & Morning: 6am-Noon & $14.63 \%(n=6)$ & $20 \%(n=3)$ & $11.54 \%(n=3)$ \\
\hline & Afternoon: Noon-6pm & $41.46 \%(n=17)$ & $40 \%(n=6)$ & $42.41 \%(n=11)$ \\
\hline & Evening: 6PM-Midnight & $43.90 \%(n=18)$ & $40 \%(n=6)$ & $46.15 \%(n=12$ \\
\hline & Night: Midnight-6am & $0 \%(n=0)$ & $0 \%(n=0)$ & $0 \%(n=0)$ \\
\hline & Total & $100 \%(\mathrm{~N}=41)$ & $100 \%(N=15)$ & $100 \%(\mathrm{~N}=26)$ \\
\hline
\end{tabular}

There was found to be no significant interaction between offence timing, either time of day or day of the week.

\subsection{Location of the Offence}

General patterns strongly indicate that offenders tend to target victims in street or road locations. Parks and wooded areas are the next most common location. Small proportions of offences occur in shops, with a very small number occurring at or around schools. The “other” locations ( $\mathrm{n}=11$ ) were as follows: Fairground; bus stop; house of mutual acquaintance during a party; internet café; outside victim’s friend’s house; train station.

Table 12: Location at Which the Offence Took Place

\begin{tabular}{|c|c|c|c|c|}
\hline & & All Offences & Completed & Attempted \\
\hline & Street or Road & $53.85 \%(n=42)$ & $49.02 \%(n=25)$ & $62.69 \%(n=17)$ \\
\hline & School & $5.13 \%(n=4)$ & $5.88 \%(n=3)$ & $3.70 \%(n=) 1$ \\
\hline Offence & Shop & $8.97(n=7)$ & $9.80(n=5)$ & $7.41 \%(n=2)$ \\
\hline Location & Park/Wooded Area & $17.95 \%(n=14)$ & $19.61 \%(n=10)$ & $14.81 \%(n=4)$ \\
\hline & Other & $14.10 \%(n=11)$ & $15.69 \%(n=8)$ & $11.11 \%(n=3)$ \\
\hline & Total & $100 \%(\mathrm{~N}=78)$ & $100 \%(n=51)$ & $100 \%(n=27)$ \\
\hline
\end{tabular}

There was found to be no statistically significant association between the location at which the offence was initiated and the outcome of the offence. The only notable trend relating to offence completion was that offences initiated on a street or road were marginally more likely 
to end as an attempt, whereas offences initiated in all other locations were more likely to end as completed abductions.

\section{Discussion}

The results indicate that there is a notable level of variation in the features of stranger child abduction when controlling for case outcome. By far the most notable findings are the interaction between an offender's background and victim sex, and the patterns observed in victim age. The overriding purpose of this paper was to examine the extent to which there are differences in the profiles of attempted cases of stranger child abduction and completed cases of stranger child abduction, with a focus on victim characteristics, offender characteristics, and offence characteristics. For all of the demographic features examined, the offending profile did indeed appear to vary depending on whether the offence became completed or not, indicating that demographics likely have a role to play with case outcome. As such, our primary hypothesis is confirmed.

\subsection{Victim Sex}

The findings pertaining to victim sex are of particular interest as they indicate that, while female victims are at more risk of being targeted by stranger child abduction overall, male victims run a greater risk of suffering a completed abduction when they are targeted. These findings observed in this study are largely consistent with those made by Newiss and Fairbrother (2004), who carried out the only other study known to specifically compare cases of attempted and completed stranger abduction. They found that, in attempts, $61 \%$ of victims were female, whereas in completed cases, this fell to 54\%. Although not quite as severe a 
difference as identified in the current study, this still indicates that there is consistent evidence that females are more present in attempted cases than male victims.

\subsection{Victim Sex Interaction with Offender Background}

Furthermore, a strong and concerning interaction was found with regard to victim sex and the interaction this has with offender background. It was found that chronic sex offenders targeted male victims significantly more frequently than they do females. In combination with the finding that generalized offenders target females victims more often, this trend could explain why offences against male victims succeed more often than they do against females. It is likely that chronic sex offenders tend to be more experienced offenders. They are likely to have carried out similar offences in the past and may have had time to consider and reflect on this type of offending in detail. As such, there is reason to suspect that such individuals are more capable of identifying suitable victims and recognizing conditions in the environment and characteristics of the victim that reduce risk to them and increase chances of success (see, e.g., Wortley \& Smallbone, 2006).

Chronic offenders are also less likely to offend in a completely opportunistic fashion. Generalized offenders, by virtue of having little specific preference for children, are more likely to be dissuaded from offending if they are met with resistance and subsequently abscond or redirect their criminogenic behaviour onto another target, which could be another child, but could also be an adult, of even a piece of property, or they may resolve their need in a less-criminogenic manner in that instance, i.e., by masturbating or watching pornography (Wortley \& Smallbone, 2006). The results appear to indicate that chronic offenders are more likely to have a specialized interest in male children, and therefore perceive fewer alternatives to meet their criminogenic needs aside from targeting male victims directly, thereby making them more persistent in their pursuit of such victims. 
An additional related finding was that the chronic sex offenders were somewhat older on average than the rest of the sample. This could be taken as further evidence of their likely persistence, given that the dataset also found that older offenders, regardless of offending background, were more likely to be persistent than younger offenders and give up later in the offence sequence. Moreover, male victims were also younger overall than female victims. Younger victims appeared less able to enact resistance techniques or recognize dangerous situations than older victims (Boudreaux, Lord \& Dutra, 1999) which replicates findings observed in research attempting to teach children for varying ages protection and safety skills (Hilme, Miltenberger, Flessner \& Gatheridge, 2004).

\subsection{Victim Age}

This examination of attempted and completed offences equips us to tentatively comment on the point put forward by Boudreaux et al. (1999) regarding why stranger child abductions seems to onset the most at school age, and why the age of 10 seems to be a recurring mean age in (most) previous studies. As a reminder, Boudreaux suggests that the reason why children of school age seem to be targeted by (sexually motivated male) stranger abductors is likely to be a combination of stranger child abduction being mostly an opportunistic offence, and because school age coincides with children receiving both more autonomy and less constant supervision whilst maintaining childhood naiveté, making them more suitable targets. The current findings can add to this. The distribution of completed cases shows a peak at age 10, as we might expect to occur given that this reflects the findings of previous studies. However, when examining attempted cases, peaks do not occur at 10, but rather at ages of 8 and of 13. This means, building on the hypothesis made by Boudreaux, Lord and Dutra (1999), that 10 is the age where a victim is most at risk of being successfully targeted by a stranger child abductor, but is not the age at which they are most likely to be targeted 
overall. This is likely by reason of this age having the greatest overlap of circumstances where protective factors are weakest, and where opportunities for offending exist.

This may also explain and reconcile discrepancies observed in the victim age patterns reported by existing studies. Self-reports identify many more offences against older victims than those reports that utilize official statistics. The patterns observed in this study appear to indicate that these older victims are able to resist the offences against them, which makes it less likely that they will not come into contact with the criminal justice system. If this is accepted, this has the further implication that stranger child abduction is actually significantly more commonly perpetrated against older victims, but that these are going unrecorded as a result of victims resisting the offence and subsequently not reporting it to relevant authorities.

\subsection{Offender Age}

The age of the offender did not appear to reveal any particularly notable patterns with reference to offence outcome. However, when examining the extent to which offenders escalated their offending beyond the mere attempt of abduction, there was a pattern whereby older offenders appeared to be more persistent in their offending than younger offenders. Younger offenders appeared to desist at an earlier occasion, or not attempt to escalate their offending at all, whereas older offenders would be more likely to escalate their offending to completion.

\subsection{Offence Characteristics}

The study appeared to show that basic offence characteristics, including offence location, time of day, and day of the week, had little to no interaction with case outcome. However, it has been useful to gather this dataset in order to provide a profile of stranger child abduction incidents. The findings confirm, as has been shown by Miller at al (2008) and Finkelhor and 
Ormrod (2000) that most offences occur in street areas, with notable numbers also occurring in parks and woodland. Day of the week appears to have little influence on case outcome, with no discernible patterns occurring aside from a limited trend whereby a greater proportion of offences fail on the weekend, however, this association was not found to be statistically significant. The findings regarding the time of day at which offences occur were inconsistent, showing only a general tendency for offences to occur later in the day. The tentative conclusion from this study, in combination with previous inconsistent results, is that offence timing has little association with offence outcome, and that there are no clear trends in offence timing that can aid in risk assessment. Given that existing findings were equally inconclusive (Miller et al, 2008; Finkelhor \& Ormrod, 2000), future work should attempt to gather more detailed information on this aspect of stranger child abduction in order to ascertain more concretely whether offence timing has any effect on case outcome.

\subsection{Future Directions}

It is recommended that future research attempt to differentiate between the behavioural patterns of stranger child abductors according to the offender's age in order to further illuminate this pattern. In addition to helping to create a clearer picture of patterns in stranger child abduction, examining this offence type according to attempted and completed cases, the findings from this study, when compared to existing work, leads to interesting possible reasons for discrepancies observed between studies. Particularly with reference to victim age patterns, the current findings are in line with trends identified by Boudreaux, Lord and Dutra (1999), where it was found that there was an increase in victimization by stranger abductors as children became more autonomous, resulting in a spike between the ages of 10 and 15 . This trend is largely replicated here, with the majority of victims falling between the spread of 10-14 years of age. This was also contemporaneous with Miller et al's. (2008, p536) work which found a similar patter when comparing abductor type with victim age. However, these 
findings, as well as the current findings are somewhat at odds with Finkelhor, Hammer and Sedlak (2002), who found that in nonfamily cases generally, victims tended to be 15 or over. The present findings showed that this was by far the least represented group, appearing only a tenth as often as Finkelhor et al. (2002) found.

It may be possible to explain this discrepancy be examining the types of data used in each study. Finkelhor, Hammer \& Sedlak (2002) combined acquaintance and stranger abductions under a single heading. Other studies, most notably Finkelhor's own previous work with Ormrod (2000), demonstrated that acquaintance abductors display a preference for victims towards the higher end of the age bracket in terms of their offending frequency. That said, Finkelhor and Ormrod (2000) also showed a steadily climbing rise in victimization frequency from school age up until the age of 15, where there was not only a peak, but a plateau. This is similarly not replicated by the present findings. This is likely due to under-representation of this age group in the present sample.

Another notable discrepancy is between present findings and Gallagher et al. (2008), who, whilst not discussing the point in much detail, showed that stranger abductions were more common among older victims than younger, with those aged 13 or over being victimized more often than those aged between 9 and 12.Those studies reporting older ages to be the average, with the exception of Finkelhor \& Ormrod (2000), incorporated self-report elements that the other studies have not. It is possible that there is a greater frequency of victimization towards older children by stranger child abductors that is not well reflected in official records. This argument would make sense since self-report based studies, such as Finkelhor, Hotaling \& Sedlak (1992) and Gallagher et al. (2008), indicated that report rates are low since cases are frequently unrecognized or dismissed as innocuous by those experiencing them. 
It is very likely that these offences would be attempted cases. Completed cases become far more likely to be reported, and hence would be more likely to be reflected in studies utilizing police data or court data (presuming conviction). An alternative explanation could be that offences against older victims are escalated more often, and hence are reported, coded and even subjectively thought of as, i.e., a rape or sexual assault and not as an abduction.

\subsection{Limitations of the Study}

The method utilized in this study has a number of unfortunate but unavoidable limitations. Firstly, the use of media and legal cases means that this data-set is likely skewed towards more serious cases that have newsworthy elements. The decision to utilize only convicted cases, although necessary for the purposes of verification, further skews the dataset towards serious offences. As such, the dataset may not accurately represent all incidences of stranger child abduction. Secondly, the sample is small. Both Gallagher et al (2008) and Newiss and Traynor (2013) reported that most cases do not go reported, which means that there is a limited number of cases that progress to the conviction stage, and even fewer that have sufficient levels of detail such that they can be fully analysed. The authors would argue that, given the exploratory nature of this study, and given the useful findings of other, similar studies examining child abduction (e.g., Shelton, Hiltz \& MacKizer, 2016), that utilizing a small but detailed sample provide a robust foundation on which to build future work.

Thirdly, a number of potentially relevant offender, victim and offence characteristics could not be identified with a sufficient level of consistency for analysis in this study, including: ethnicity and nationality of offenders; ethnicity and nationality of victims; offender employment (current and historical); offender education level; offender family background; and offender marital status. Their absence is due to these factors not being routinely recorded by police, the media, or the courts. These characteristics have been found to be important in 
other studies (i.e., Shelton, Hiltz \& MacKizer, 2016), and it is recommended that future studies attempt to gather information pertaining to these.

These drawbacks are regrettable; however, this data represents the best information currently available on this population. Most offences of stranger child abduction are not brought to the attention of authorities, and when they are, there are a number of recording issues, including potentially relevant demographic details not being noted, and their being inadequate distinctions between acquaintance and stranger abductions (see Newiss \& Traynor, 2013). As a result, the current small, relatively un-representative sample represents the only source of data where an acceptable level of detail on this population exists, and could be readily accessed by researchers.

\section{Conclusions}

This largely exploratory study, despite having a fairly small sample with limited representativeness, appears to demonstrate that the profile of stranger child abduction alters to notable degree when completed offences are compared to attempted offences.

The direct findings from this study raise a number of questions that should be prioritized in further research, and could even necessitate practical change in how we treat such offences. In particular, the finding that males and females have such distinct victimization patterns in terms of how often offences are completed against them, as well as in what kind of offenders target them, requires further exploration and explanation. Of similar importance, the findings indicate that additional measures are required to protect children aged closer to 10, making it useful to examine which features make them particularly vulnerable and what countermeasures could be viable. It may also be necessary to re-evaluate how children are 
taught to resist such offences, given the distinct risks faced by children of various sexes and age groups.

The primary avenue for investigation with regard to offenders alluded to by these findings would be the extent of offender persistence. It appears that certain offender featuresparticularly age and offending background- interact with how likely they are to pursue a single offending opportunity rather than to discontinue their offending or migrate to other offences. Further examination of offender characteristics as they pertain to abduction offence outcome, a notable gap left by the few previous studies examining this issue (notably Finkelhor, Hotaling\& Asdigian, 1995) bears further examination.

At a practical level for researchers, this leads to an endorsement of continuing to analyse stranger child abduction cases according to the attempted-completed distinction. It will be extremely useful for future researchers if agencies involved with recording information pertaining to such behaviour distinguish between attempted and completed cases when taking information. It will also be useful if researchers take care to notify readers of the proportions of attempted and completed cases in future work on this topic, which will be especially useful in avoiding future, problematic discrepancies in analysis caused by inappropriately treating these distinct typologies as one.

In addition to the questions raised by the specific findings of this paper, it would be particularly useful if other important offending features present in stranger child abduction be compared according to offence outcome. Initial recommendations would be to analyse commonly recorded crime features such as abduction site, use of vehicles, and use of tools and weapons, as this information is likely to be relatively easy to collect while also representing valuable avenues for investigation that would be likely to reveal valuable further information with regard to the profile of stranger child abduction. 


\section{References}

Asdigian, N. L., Finkelhor, D., \& Hotaling, G. (1995).Varieties of nonfamily abduction of children and adolescents. Criminal Justice and Behaviour, 22, 215-232.

Baker, T., Burgess, A. W., Rabun, J. B., \& Nahirny, C. (2002).Abductor violence in nonfamily infant kidnapping. Journal of Interpersonal Violence, 17(11), 1218-1233.

Beasley, K.R., \& Beyer, J.O. (2003). Nonfamily child abductors who murder their victims:

Offender demographics from interviews with incarcerated offenders. Journal of Interpersonal Violence, 18, 1167-1188.

Beasley, J.O., Hayne, A.S., Beyer, K., Cramer, G.L., Berson, S.B.., Muirhead, Y., Warren, J.I. (2009). Patterns of prior offending by child abductors: A comparison of fatal and nonfatal outcomes. International Journal of Law and Psychiatry, 32, 273-280.

Beauregard, E., Stone, M.R., Proulx, J., \& Michaud, P. (2008). Sexual murderers of children: Developmental, precrime, crime and postcrime factors. International Journal of Offender Therapy and Comparative Criminology, 52, 253-268. 
Best, J. (1987). Rhetoric in claims-making: Constructing the missing children problem. Social Problems, 34(2), 101-121.

Best, J. (1988).Missing children, misleading statistics. Public Interest, 92, 84-92.

Best, J. (1989). Dark figures and child victims: statistical claims about missing children. In Images of Issues. (Best, J.). (Ed.).21-37. New York: Aldine de Gruyter.

Best, J. (1993).Threatened children: Rhetorical concern about child victims. Chicago: University of Chicago Press.

Boudreaux, M.C., Lord, W.D., \& Dutra, R.L. (1999). Child abduction: Aged-based analyses of offender, victim, and offence characteristics in 550 cases of alleged child disappearance. Journal of Forensic Science, 44 (3), 539-553.

Brown, K.M., Keppel, R.D., Weis, J.G., \& Skeen, M.E. (2006).

Erikson, M., \& Friendship, C. (2002).A typology of child abduction events. Legal and Criminological Psychology, 7. 
Finkelhor, D., Hammer, H., \& Sedlak, A.J. (2002).Nonfamily abducted children: National estimates and characteristics. Washington: US Department of Justice.

Finkelhor, D., Hotaling, G., and Sedlak, A. (1992). The abduction of children by strangers and nonfamily members: Estimating the incidence using multiple methods. Journal of Interpersonal Violence 7(2):226-243.

Finkelhor, D., Hotaling, G., \& Asdigian, N. (1995).Attempted non-family abductions. Child Welfare, 34, 941-955

Finkelhor, D., \& Ormrod, R. (2000).Kidnapping of juveniles: Patterns from NIBRS. Washington: US Department of Justice: Office of Juvenile Justice and Delinquency Prevention.

Fitzgerald, J., \& People, J. (2006). Victims of abduction: Patterns and case studies. BOCSAR NSW Crime and Justice Bulletins, 16.

Francis, B., \& Soothill, K. (2010). Does sex offending lead to homicide? Forensic Psychiatry and Psychology, 11(1), 49-61. 
Gallagher, B., Bradford, M., \& Pease, K. (2008). Attempted and completed incidents of child-perpetrated child sexual abuse and abduction. Child Abuse and Neglect, 32, 517-528

Gregoire, C.O. (2010). Case management for missing children homicide investigation. Washington: Office of the Attorney General. Retrieved on $14^{\text {th }}$ October 2015 from http://www.pollyklaas.org/media/pdf/Abduction-Homicide-Study.pdf

Griffin, T., \& Miller, M.K., (2008). Child abduction, AMBER Alert, and crime control theater. Criminal Justice Review. 33(2), 159-176.

Hanfland, K.A., Keppel, R., \& Weis, J. (1997).Case management for missing children homicide investigation. Washington: US Department of Justice, Office of Juvenile Justice and Delinquency Prevention.

Heide, K.M., Beauregard, E., \& Myers, W.C. (2009). Sexually motivated child abduction murders: Synthesis of the literature and case illustration. Victims \& Offenders: An international Journal of Evidence-based Research, Policy, and Practice, 4(1), 58-75.

Himle M.B, Miltenberger R.G, Flessner C, Gatheridge B.J. (2004). Training and generalization of skills to prevent gun play in children. Journal of Applied Behavior Analysis, 37, 1-9.

Jennings, W. G., Piquero, A.R., Zimrig, F.E., \& Reingle, J.M. (2015). Assessing the Continuity of Sex Offending Over the Life Course. Evidence from two large British cohort 
studies. In Blokland, A., \& Lussier, P. (2015). (Eds.). Sex offenders: A criminal career approach. Chichester: John Wiley \& Sons.

Johnston, J.R., Sagatun-Edwards, I., Blomquist, M.E., \&Girdner, L.K. (2001).Early identification of factors for parental abduction. Juvenile Justice Bulletin, March 2001. U.S. Department of Justice, Office of Juvenile Justice and Delinquency Prevention.

Lanning, K. V., \& Burgess, A. W. (Eds.). (1995). Child Molesters Who Abduct: Summary of the Case in Point Series. National Center for Missing and Exploited Children.

Liu, J., Francis, B., \&Soothill, K. (2007). Kidnapping offenders: Their risk of escalation to repeat offending and other serious crime. Journal of Forensic Psychiatry and Psychology, 19(2), 164-179.

Miller, J., Kurlycheck, M., Hansen, A.J., \& Wilson, K. (2008).Examining child abduction by offender type patterns. Justice Quarterly, 25.

Newiss, G. (2014). Beyond Stranger Danger: Teaching children about staying safe from stranger child abduction. London: Parents and Abducted Children Together. Retrieved August $26^{\text {th }}$, 2015, from http://www.childabduction.org.uk/index.php/publications 
Newiss, G., \& Tranynor, M.A. (2013).Taken: A study of child abduction in the UK. London: PACT.

Noor-Mohammed, M.K. (2013). The definitional ambiguities of kidnapping and abduction, and its categorization: The case of a more inclusive typology. Howard Journal of Criminal Justice, DOI: 10.1111/hojo.12028

Office of National Statistics (2011).Usual resident population. KS101EW. Retrieved on $20^{\text {th }}$ October 2015 from http://www.nomisweb.co.uk/census/2011/KS101EW/view/2092957703?cols=measures

Prentky, R. A., Knight, R. A., Burgess, A. W., Ressler, R., Campbell, J., \& Lanning, K. V. (1991). Child molesters who abduct. Violence and victims, 6(3), 213-224.

Proulx, J., Perreault., C., \& Ouimet, M. (1999). Pathways in the offending process of extrafamilial child molesters. Child Abuse: A Journal of Research and Treatment, 11(2), 117129.

Rodreguez, R. D., Nahirny, C., Burgess, A. W., \& Burgess, A. G. (1998). Missing children found dead. Journal of psychosocial nursing and mental health services, 36(6), 11-16. 
Shelton, J., Hilts, M., \& MacKizer, M. (2016). An exploratory study of residential child abduction: An examination of offender, victim and offense characteristics. Aggression and Violent Behavior.

Spilman, S.K. (2006). Child abduction, parents' distress, and social support. Violence and Victims, 21(2), 149-165.

Wortley, R., \& Smallbone, S. (2006). Applying situational principles to sexual offences against children. In R. Wortley, \& S. Smallbone. (2006). (Eds.).Situational prevention of child sexual abuse. Child Prevention Studies, 19. Monsey: Criminal Justice Press. 